\title{
EVALUATION OF APICAL DEVIATION IN ROOT CANALS INSTRUMENTED WITH K3 AND ProTaper SYSTEMS
}

\author{
AVALIAÇÃO DO DESVIO APICAL EM CANAIS INSTRUMENTADOS PELOS SISTEMAS K3 \\ E ProTaper
}

Mariana Diniz Bisi dos SANTOS ${ }^{1}$, Marília Fagury MARCELIANOํㅜ, Patrícia Rodrigues de Almeida SILVA E SOUZA ${ }^{2}$

1- DDS, Undergraduate student, Centro Universitário do Pará.

2- DDS, MSc, PhD, Full Professor, Departament of Endodontics, Centro Universitário do Pará.

Corresponding address: Mariana Diniz Bisi dos Santos - Rua Diogo Moia, n. 380, apt. 1601, Umarizal - CEP: 66055-170, Belém, PA, Brazil Phone +55 (91) 32230237 or +55 (91) 99822502 - e-mail: marianabisi@hotmail.com

Received: April 18, 2006 - Modification: July 3, 2006 - Accepted: December 6, 2006

\begin{abstract}
$O$ bjectives: this study evaluated the apical deviation of curved root canals instrumented with K3 and ProTaper systems. Material and methods: twenty root canals of human maxillary and mandibular first molars were employed, which were divided into 2 groups: group A (10 teeth) was instrumented with the K3 system, and group B (10 teeth) with the ProTaper system. Evaluation of deviation was performed by double radiographic exposure. Radiographs were achieved before and after instrumentation, with 0.3-second, thus allowing superimposition of images. Three-dimensional computerized tomograph was performed in 3 specimens in each group, as an additional means to evaluate the apical deviation. Results: were evaluated by the parametric test Student-Newman-Keuls at 5\%, which did not reveal significance between groups concerning the apical deviation. The results of computerized tomograph images demonstrated that the larger deviation of the root canal occurred at the distolingual area for both systems. Conclusions: both techniques produced a mild apical deviation. Computerized microtomography was shown to be accurate for experimental endodontics studies.
\end{abstract}

Uniterms: Root canal, instrumentation; K3.

\section{RESUMO}

$O$

bjetivos: avaliar o desvio apical de canais radiculares curvos instrumentados pelos sistemas K3 e ProTaper. Material e métodos: foram utilizados 20 canais radiculares de primeiros molares superiores e inferiores humanos, os quais foram divididos em 2 grupos, o grupo A (10 dentes) foi instrumentado pelo sistema K3 e o grupo B (10 dentes) com o sistema ProTaper, a forma de avaliação do desvio foi a dupla exposição radiográfica. As tomadas radiográficas foram feitas antes e após a instrumentação, com um tempo de 0,3 segundos em cada exposição, ocorrendo assim, sobreposição das imagens. Em 3 espécimes, de cada grupo, foi realizada a tomografia computadorizada tridimensional, como forma adicional de avaliar o desvio apical . Os resultados obtidos foram avaliados pelo teste paramétrico Student-Newman-Keuls 5\% o qual denotou não haver significância em relação ao desvio apical entre os grupos estudados. Os resultados das imagens de tomografia computadorizada mostraram que o maior desvio do canal radicular ocorreu na área disto-lingual, para ambos os sistemas estudados. Conclusão: ambas as técnicas promoveram desvio apical. A tomografia computadorizada revelou ser um método de análise promissor em estudos in vitro na área de endodontia.

Unitermos: Canal radicular, instrumentação; K3. 


\section{INTRODUCTION AND LITERATURE REVIEW}

The greatest difficulties in endodontic therapy occur at the instrumentation stage, due to anatomical complexities that may lead to errors and accidents. Until the 1960s, root canal preparation consisted of flaring using sequentially larger manual files throughout the root canal, until proper width was reached for obturation. Thus, accidents occurred very often, since the root canal anatomy and limited flexibility of instruments were not respected. In 1969, Clem ${ }^{4}$ suggested differentiated preparation at each root canal third, through which the apical region, which is thinner and curved, should be prepared with thinner and more flexible instruments, whereas the middle and cervical thirds could be more enlarged to allow achievement of proper taper.

There was a remarkable technical advance; however, instruments presented limitations as to following the original root canal configuration, due to their little flexibility. Walia, et al. ${ }^{14}$ (1988) advocated utilization of a new nickel-titanium alloy for fabrication of endodontic instruments, which were then fabricated with stainless steel.

Simultaneously, with a view to reduce the working time and operator's fatigue, an endodontic instrument was developed for rotary application in the root canal. The flexibility of NiTi instruments allowed $360^{\circ}$ rotation in curved root canals without occurrence of root canal deviation.

Undoubtedly, utilization of the Ni-Ti alloy associated with a new design of endodontic files and improvement of instrumentation techniques contributed for a new age in Endodontics, characterized by faster instruments with higher quality.

Among the rotary systems, the K3 (Kerr) and ProTaper (Dentsply-Maillefer) systems have been presenting good properties and effective preparation.

Schafer and Florek ${ }^{11}$ (2003) conducted a study to compare the ability of shaping of simulated root canals, comparing rotary files K3 and manual stainless steel files K-Flexofile. The authors observed that the K3 instrument provided better root canal geometry and less root canal transportation. In the same year, Schafer and Schlingemann ${ }^{12}$ evaluated the same system in extracted human teeth and found that the KFlexofile instrument promoted larger removal of debris, whereas the K3 system maintained the original root canal curvature.

Yun and $\mathrm{Kim}^{13}$ (2002) compared four different types of rotary Ni-Ti systems: ProFile, GT Rotary, Quantec and ProTaper. The ProTaper system required shorter preparation time and promoted larger wear of the root canal curvature. One year later, Peters, et al. ${ }^{10}$ evaluated the performance of ProTaper Ni-Ti instruments in root canal shaping and concluded that the volume and surface area were significantly increased, regardless of the type of root canal.

Bergmans, et al. ${ }^{2}$ (2003) evaluated the influence of constant taper (K3 system) and progressive taper (ProTaper system) on root canal instrumentation and concluded that progressive taper has less influence on the wear of root canal curvatures than instruments with continuous taper, which provide good apical centralization.

It is noticed that there is a constant concern of investigators to develop an instrumentation system that allows increased productivity with maintenance of efficiency in root canal shaping. Thus, the present study was conducted to compare the instruments of $\mathrm{K} 3$ and ProTaper systems as to maintenance of the original root canal configuration in teeth with curved root canals.

\section{MATERIALAND METHODS}

The sample was composed of 20 mesiobuccal roots, with mean curvature of $39^{\circ}$. The working length was determined at $1 \mathrm{~mm}$ on this side of the apical foramen. To determine this point, a $\mathrm{K}$ instrument was introduced in catheterism movement until the instrument tip was visualized through the foramen; at this moment, the length was verified and reduced in $1 \mathrm{~mm}$.

After that, the roots were embedded in self-curing acrylic resin blocks to allow biomechanical preparation and positioning of roots for achievement of radiographs.

The method employed in the present study for evaluation of apical deviation was double radiographic exposure; thus, the first radiograph was obtained with the initial instrument at the working length. After instrumentation, another radiograph was taken on the same film, also with the file at the working length. The exposure time for each radiograph was 0.3 second.

The images obtained by double exposure were standardized with aid of a specially designed device (Figure 1 ), so that the tooth, radiographic film and X-ray were always at the same position.

The teeth were divided into two groups: Group A was instrumented with the K3 system following the sequence: 25/10, 25/08, 30/06, 30/04, 25/06 and 25/04. Apical stop was determined with 30/04 instrument.

Group B was treated with the ProTaper system, following the sequence: SX for cervical preparation and S1, S2, F1, F2, $\mathrm{F} 3$, all in the working length.

Both groups were treated using a crown-down technique and the instruments were operated at $300 \mathrm{rpm}$ using a slow-

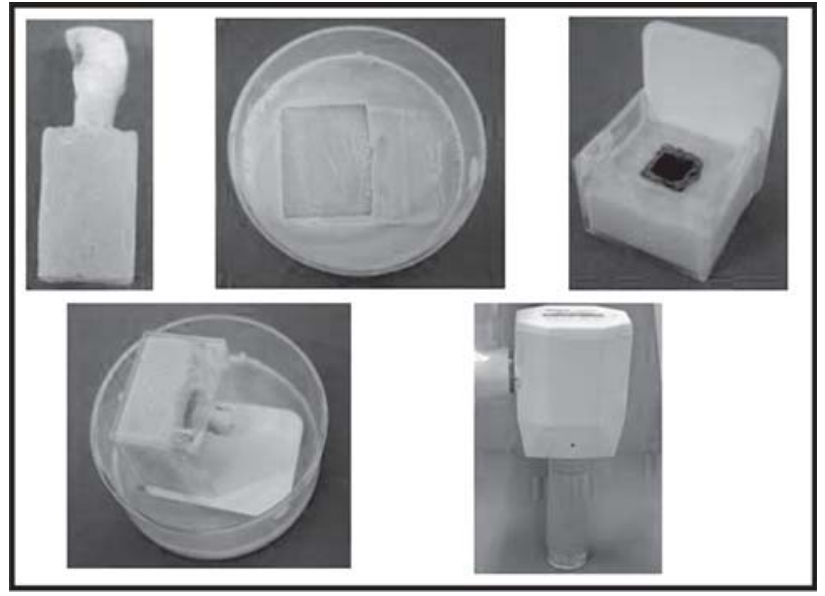

FIGURE 1- Device for achievement of radiographs 
speed high-torque endodontic electric motor (Endo Plus / VK Driller, São Paulo, São Paulo), with a 16:1 gear reduction handpiece. During instrumentation, the torque was modified in accordance with the manufacturer's guidelines for each instrument, so that the torque varied from 1 to $3 \mathrm{~N}$. All instrumentation was done with $1 \%$ sodium hypochlorite as irrigant solution.

Radiographs were developed and scanned for measurement of apical deviation. The difference between initial and final positioning of the instrument at the three levels at the apical third was measured in mm on the image analysis software ImageTool (Figure 2).

These data were plotted and statistically valuated by the parametric test Student-Newman-Keuls at $5 \%$.

An additional evaluation was performed in this study by three-dimensional computerized tomography GE Medical Systems, with 1-mm slices for measurement of areas with larger apical deviation at the apical and middle root canal thirds after instrumentation. This analysis was performed on three roots of each group. Similarly as for the radiographic evaluation, a device was designed for achievement of images with standardized positioning of specimens before and after preparation.

Two transverse sections were obtained. Two straight lines were traced in buccolingual and mesiodistal direction on the 2 images, through the tooth center and exactly at intersection between the two lines ( $\mathrm{Y}$ and $\mathrm{X}$ ), for achievement of the 0 value. Four further straight lines were traced from this point: distobuccal, mesiobuccal, distolingual and mesiolingual; distances were measured on the ImageTool software. Measurements before and after instrumentation were recorded for later comparison.

The area with the highest frequency of deviation was analyzed for both study groups.

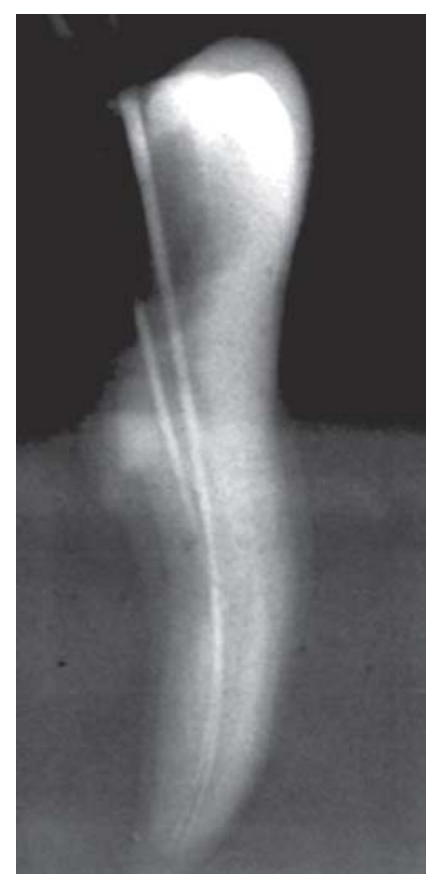

FIGURE 2- Radiographic image for measurement of apical deviation

\section{RESULTS}

The means achieved were submitted to the parametric test Student-Newman-Keuls at 5\%, which revealed a p value of 0.7910 , thus without significant apical deviation between the study groups.

Evaluation by computerized tomograph revealed that the larger deviation of the root canal occurred at the distolingual area, for teeth instrumented with K3 and ProTaper systems, at the apical and middle thirds.

\section{DISCUSSION}

Each rotary system presents a different design of active point to provide more uniform preparations. The K3 system presents constant taper and radial lands, besides other characteristics, which allow achievement of root canal taper and centralization, respectively. On the other hand, the ProTaper system presents progressive taper, which allows more uniform preparation².

Another important aspect that should be considered in utilization of rotary systems is the direction of preparation ${ }^{1,5}$. This type of preparation, combined to the different tapers of each instrument, allows progressive removal of dentinal interferences along the root canal, avoiding root canal instrumentation under pressure, thereby reducing the levering effect, which leads to increased wear at the furcation region, middle third, and mesial root canal wall at the apical third.

Even though both systems investigated present different designs of active point, both produced mild deviation at the apical region, with rectification of the internal root canal anatomy when cutting instruments are used. Different results were obtained by others studies as Peru et al. ${ }^{8}$ and Guelzow et al. ${ }^{6}$, who demonstrated that these systems were able to maintain the canal curvature. Some studies demonstrated the influence of cervical preflaring with Gates Glidden burs on the degree of apical transportation; this probably had a significant influence in the present study.
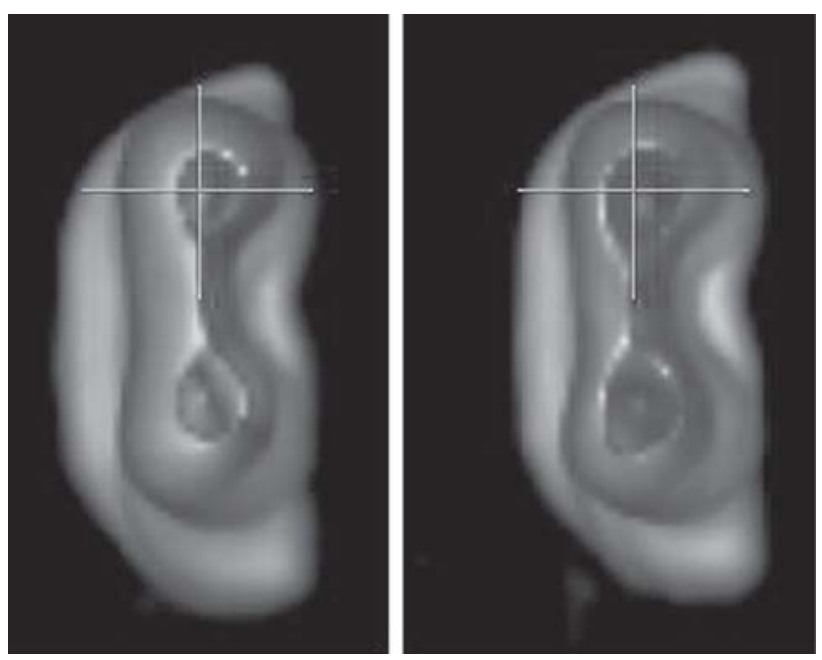

FIGURE 3- Computerized tomographic image before and after instrumentation 
Therefore, it is suggested that only the use of both systems is not enough to remove cervical dentin interferences.

As demonstrated by Bergmans et al. ${ }^{2}$ (2003), the radial lands of the K3 instrument allow better root canal centralization, whereas the ProTaper system produces less wear at the curved root canal wall. It is noticed that modifications in instrument design are attempts to compensate for the influence of root canal anatomy. The two systems have a different design, but the ability to maintain the canal curvature was the same. The similar composition and applied technique could probably explain the same behavior.

According to the literature, utilization of threedimensional computerized tomograph as an option to evaluate preparation is very effective, since it does not require tooth sectioning, which leads to structure loss ${ }^{3,9}$. This analysis was performed on 3 randomly selected roots of each group, adding up to 6 teeth. Studies conducted by Bjornal, et al. ${ }^{3}$ (1999), Peters, et al. ${ }^{10}$ (2003) and Bergmans, et $\mathrm{al}^{2}$ (2003) demonstrated that there was no need of larger samples, since the computerized tomograph provides images with proper sharpness.

The computerized tomographic images revealed occurrence of more wear of the root canal at the distolingual area, following the anatomical direction of mesiobuccal canals, in teeth instrumented with both K3 and ProTaper systems, at the apical and middle thirds. Bergmans, et al. ${ }^{2}$ (2003) noticed the difference between the two systems, being that the ProTaper system produced more deviation at the furcation region and the K3 system produced larger apical deviation. Yun and $\mathrm{Kim}^{13}$ (2002) compared the ability of root canal shaping of the ProFile, GT Rotary, Quantec and ProTaper systems and observed that the group instrumented

TABLE 1- Descriptive analyses of experimental group

\begin{tabular}{llll}
\hline GROUP & No OF SAMPLE & MEAN & $\begin{array}{l}\text { STANDARD } \\
\text { DEVIATION }\end{array}$ \\
\hline A & 08 & 0.2488 & 0.2042 \\
B & 08 & 0.1588 & 0.1841 \\
\hline
\end{tabular}

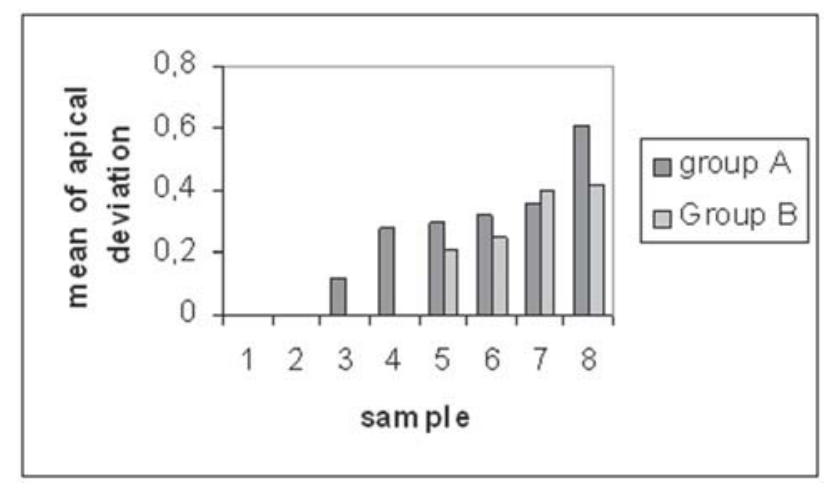

FIGURE 4- Comparison of apical deviation between group $A$ and group $B$ with the ProTaper system presented the largest wear in the root canal curvature, thus with higher rectification.

In the study carried out by Nielsen et al. ${ }^{7}$ (1995), as well as in this study, equal findings were observed, such as: the possibility to verify the potential use of computerized tomography in endodontics studies; the ability to accurately work on the external and internal morphologies of teeth without destruction, the possibility of showing changes over time in surface areas and volumes of tissues, the ability to assess area and volume changes after instrumentation or obturation, and the capability of evaluating canal transportation following instrumentation.

Analysis of the literature and the present results reveal that there is still deviation of the original root canal configuration, despite the utilization of systems with adequate properties. It should be highlighted that deviations observed were small and possibly would not interfere with treatment success with regard to root canal shaping; further studies are required to confirm this assumption.

\section{CONCLUSION}

Considering the results achieved in both analyses and the methodological limitations of the present study, it was concluded that both techniques produced apical deviation. Computerized microtomography was shown to be accurate for experimental endodontics studies.

\section{REFERENCES}

1- Abou-Rass M, Frank Al, Glick DH. The anticurvature filing method to prepare the curved root canal. J Am Dent Assoc. 1980;101(5):7924.

2- Bergmans L, Van Cleynenbreugel J, Beullens M, Wevers M, Van Me B, Lambrechts P. Progressive versus constant tapered shaft design using NiTi rotary instruments. Int Endod J. 2003;36(4):288-95.

3- Bjorndal L, Carlsen O, Thuesen G, Darvann T, Kreiborg S. External and internal macromorphology in 3D-reconstructed maxillary molar using computerized X-ray microtomography. Int Endod J. 1999;32(1):3-9.

4- Clem Wh. Endodontics: the adolescent patient. Dent Clin North Amer. 1969;13:483-93.

5- Goerig Ac, Michelich Rj, Schultz Hjh. Instrumentation of root canals in molar using the step-down technique. J Endod. 1982;8:5504.

6- Guelzow A, et al. Comparative study of six rotary nickel-titanium systems and hand instrumentation for root canal preparation. Int Endod J. 2005;38(10):743-52.

7- Nielsen Rb, et al. Microcomputed tomography: an advanced system for detailed endodontic research. J Endod. 1995;21(11):561-8.

8- Peru M, et al. Hand and nickel-titanium root canal instrumentation performed by dental students: a micro-computed tomografic study. Eur J Dent Educ. 2006; 10(1):52-9. 
9- Peters Oa, Laib A, Barbakow F, Ruegsegger P. Three-dimensional analysis of root canal geometry by high-resolution computed tomography. J Dent Res. 2000;79(6):1405-9.

10- Peters Oa, Peters Ci, Schonenberger K, Barbakow F. Pro-Taper rotary root canal preparation: assessment of torque and force in relation to canal anatomy. Int Endod J. 2003;36:93-9.

11- Schafer E, Florek H. Efficiency of rotary nickel-titanium K3 instruments compared with stainless steel hand K-Flexofile. Part 1. Shaping ability in simulated curved canals. Int Endod J. 2003;36:199207.

12- Schafer E, Schlngemann R. Efficiency of rotary nickel-titanium K3 instruments compared with stainless steel hand K-Flexofile. Part 2.Cleaning effectiveness and shaping ability in severely curved root canals of extracted teeth. Int Endod J. 2003;36:208-17.

13- Yun Hh, Kim Sk. A comparison of shaping abilities of 4 nickeltitanium rotary instruments in simulated root canals. Oral Surg Oral Med Oral Pathol Oral Radiol Endod. 2003;95:228-33.

14- Walia H, Brantley Wa, Gerstein H. An initial investigation of the bending and torsional properties of nitinol root canal files. J Endod. $1988 ; 14(7): 346-51$ 